\title{
Gestión integral de COVID 19 en un hospital regional en el noroeste de España
}

\author{
Cristina Sardiña-González, Manuel Lorenzo López-Reboiro, Rebeca Suárez-Fuentetaja, \\ Beatriz Ares Castro-Conde, Enrique Álvarez-Asensio y José López-Castro* \\ Hospital Público de Monforte, Departamento de Medicina Interna, Lugo, España
}

\begin{abstract}
Resumen
Introducción: La pandemia de COVID-19 provocó un cambio de paradigma en la atención médica. Objetivo: Evaluar una estrategia para abordar integralmente la pandemia en un distrito de salud que comprende 42000 personas. Método: Entre el 10 de marzo y 15 de mayo de 2020 se creó la Unidad COVID en un hospital regional correspondiente al distrito y se estableció un circuito independiente para el diagnóstico y manejo de pacientes con sospecha o confirmación de COVID-19; los centros de salud social fueron monitoreados mediante PCR. Resultados: Ingresaron 18 pacientes positivos a COVID-19 (edad de $72.9 \pm 13.2$ años), 66 \% eran hombres; todos presentaron neumonía, 67 \% desarrolló síndrome de dificultad respiratoria y ninguno requirió ventilación mecánica. La estancia hospitalaria fue de $9.4 \pm 5.3$ días y la mortalidad, de $11 \%$. Se realizaron pruebas de PCR a todos los residentes $(n=827)$ y trabajadores $(n=519)$ del hospital, se realizaron 1044 llamadas telefónicas y se evitaron 36 hospitalizaciones. Solo 50 pacientes necesitaron seguimiento cercano, cuatro $(0.48 \%)$ positivos a COVID-19. Conclusión: El monitoreo clínico en el hospital y centros de salud social mostró que el perfil de los pacientes fue similar al documentado en la literatura y que la incidencia de COVID-19 fue baja en los centros sociales de salud.
\end{abstract}

PALABRAS CLAVE: COVID-19. Salud pública. Estrategias integrales de salud.

\section{COVID 19 comprehensive management in a regional hospital of Northwestern Spain}

\section{Abstract}

Introduction: The COVID-19 pandemic has brought about a paradigm shift in healthcare. Objective: To evaluate the utility of a strategy to comprehensively address the pandemic in a health area that covers 42,000 people. Method: Between March 10 and May 15, 2020, the COVID Unit was created in the corresponding regional hospital, and an independent circuit was established for the diagnosis and management of patients with suspected or confirmed COVID-19; social health centers were monitored with PCR testing. Results: Eighteen COVID-19-positive patients (age $72.9 \pm 13.2$ years) were admitted, out of which $66 \%$ were males. All these patients had pneumonia and $67 \%$ had respiratory distress syndrome; no one required mechanical ventilation. Mean hospital stay was $9.4 \pm 5.3$ days, and mortality, $11 \%$. PCR tests were applied to all hospital residents $(n=827)$ and workers $(n=519), 1,044$ phone calls were made and 36 hospital admissions were avoided. Only 50 patients required close follow-up, out of which four (0.48\%) were positive for COVID-19. Conclusion: Clinical monitoring at the hospital and social health centers showed that patient profile was like that documented in the literature and that the incidence of COVID-19 was low in social health centers.

KEY WORDS: COVID-19. Public health. Comprehensive health strategies.

Correspondencia:

*José López-Castro

E-mail: jlcastro126@ hotmail.com
Gac Med Mex. 2020;156:294-297

Disponible en PubMed

www.gacetamedicademexico.com

0016-3813/৫ 2020 Academia Nacional de Medicina de México, A.C. Publicado por Permanyer. Este es un artículo open access bajo la licencia CC BY-NC-ND (http://creativecommons.org/licenses/by-nc-nd/4.0/). 


\section{Introducción}

La pandemia de COVID-19 representa un desafío para todos los sistemas de salud. ${ }^{1}$ En un periodo muy corto ha obligado a la toma de decisiones para administrar la atención de los pacientes con esta enfermedad, así como la demarcación de circuitos diferenciados para evitar el contacto entre pacientes no infectados, pacientes sospechosos o confirmados de COVID-19, para lo cual se han creado nuevas salas de aislamiento en los hospitales y se han ampliado las salas de cuidados intensivos y de cuidados intermedios.

Los médicos hemos tenido que lidiar con la incertidumbre de no conocer la evolución o los tratamientos específicos de la enfermedad, y con situaciones desconocidas contra reloj. ${ }^{2}$ Los ancianos institucionalizados (residentes en centros geriátricos, que incluyen viviendas protegidas y para personas con discapacidades) son el grupo más vulnerable, tanto al contagio como a la mortalidad asociada a la infección por COVID-19, no solo por la edad sino porque presentan más comorbilidades y menor capacidad intrínseca, tanto cognitiva como funcional.

Conforme a la investigación que realizamos, el estudio que a continuación presentamos es el primero en combinar el monitoreo clínico de COVID-19 en un hospital regional y en los centros de salud social del mismo distrito sanitario.

\section{Método}

Se realizó un estudio observacional prospectivo en el Hospital Público de Monforte, en Lugo, España, hospital regional con 141 camas que atiende a un distrito de salud de 42000 personas y cuyo hospital de referencia es el Hospital Universitario Lucus Augusti, en la misma ciudad. La Unidad COVID está compuesta por médicos de medicina interna y una geriatra, quienes trabajaban en una red con atención primaria, centros de salud social y hospitalización domiciliaria. Se elaboró un plan de coordinación con las 11 residencias sociosanitarias o geriátricas del distrito, con las cuales se lleva a cabo seguimiento telefónico activo diario a través de una enfermera administradora de casos, para identificar a los pacientes que requieren intervención. Los pacientes son clasificados en dos grupos:

- Pacientes sin patología respiratoria infecciosa, con el fin de reducir los ingresos hospitalarios y las visitas al departamento de emergencias, tratando de favorecer la atención médica en el entorno residencial (en las residencias que no dispongan de un médico o personal de enfermería que trabaje con el equipo de hospitalización domiciliaria y la colaboración de atención primaria).

- Pacientes con síntomas respiratorios infecciosos, que según su fenotipo se identificaron como robustos y frágiles.

Se realizó estadística descriptiva para conocer el perfil del paciente con COVID-19 y la reducción de ingresos hospitalarios con la aplicación de este sistema de trabajo.

\section{Aspectos éticos}

Todos los pacientes firmaron el consentimiento informado y su manejo se realizó de acuerdo con los documentos publicados recientemente por el Ministerio de Salud, Consumo y Bienestar Social de España.

\section{Resultados}

Solo los pacientes con COVID-19 y algún factor de riesgo o complicación fueron candidatos para ingreso hospitalario (los pacientes asintomáticos fueron seguidos en el lugar de residencia). Se admitieron 21 pacientes, de los cuales se excluyeron tres: dos que fueron transferidos al centro de referencia y otro cuyo diagnóstico de COVID-19 se estableció 15 días antes y en todo momento se encontró asintomático; su ingreso al hospital se debió a aneurisma aórtico abdominal.

Los 18 pacientes restantes tenían una edad promedio de $72.9 \pm 13.2$ años, la mayoría de ellos fue del sexo masculino (66 \%) y solo $11 \%$ perteneció al sector de la salud. En cuanto a la comorbilidad, $50 \%$ presentaba hipertensión, $17 \%$ broncopatía y $17 \%$, obesidad. El $88 \%$ de ellos calificó con tres puntos 0 más en el índice de comorbilidad de Charlson ajustado por edad.

Predominaron los síntomas respiratorios, disnea (78\%) y tos (61\%), seguidos de síntomas gripales: astenia (56\%), artromialgia (33\%) y anorexia (28\%). La ageneusia y la anosmia, síntomas altamente sugestivos de COVID-19, solo se observaron en 11 y $17 \%$, respectivamente. Los síntomas gastroabdominales se manifestaron en una minoría; $17 \%$ indicó diarrea y $5 \%$, náuseas. Todos los pacientes presentaron neumonía y $67 \%$, síndrome de dificultad respiratoria; ninguno requirió ventilación mecánica no invasiva. Los tratamientos utilizados fueron azitromicina e hidroxicloroquina (87\%), ritonavir y lopinavir (78\%), interferón 
Tabla 1. Datos clínico-terapéuticos, complicaciones y evolución de 18 pacientes con COVID-19 atendidos en el Hospital Público de Monforte, España

\begin{tabular}{|c|c|c|}
\hline Edad en años (media \pm DE) & \multicolumn{2}{|c|}{$72.9 \pm 13.2$} \\
\hline Días de estancia hospitalaria (media $\pm \mathrm{DE}$ ) & \multicolumn{2}{|c|}{$9.4 \pm 5.3$} \\
\hline & n & $\%$ \\
\hline Sexo masculino & 12 & 67 \\
\hline Personal sanitario & 2 & 11 \\
\hline $\begin{array}{l}\text { Comorbilidad } \\
\text { Hipertensión arterial } \\
\text { Broncopatía } \\
\text { Obesidad } \\
\text { Índice de Charlson } \geq 3\end{array}$ & $\begin{array}{c}9 \\
3 \\
3 \\
14\end{array}$ & $\begin{array}{l}50 \\
17 \\
17 \\
78\end{array}$ \\
\hline $\begin{array}{l}\text { Manifestaciones clínicas } \\
\text { Disnea } \\
\text { Tos } \\
\text { Astenia } \\
\text { Artromialgia } \\
\text { Anorexia } \\
\text { Ageneusia } \\
\text { Anosmia } \\
\text { Diarrea } \\
\text { Náuseas } \\
\text { SDR }\end{array}$ & $\begin{array}{c}14 \\
11 \\
10 \\
6 \\
5 \\
2 \\
3 \\
3 \\
1 \\
12\end{array}$ & $\begin{array}{c}78 \\
61 \\
56 \\
33 \\
28 \\
11 \\
17 \\
17 \\
5 \\
67\end{array}$ \\
\hline $\begin{array}{l}\text { Tratamiento } \\
\text { Azitromicina } \\
\text { Hidroxicloroquina } \\
\text { Lopinavir-ritonavir } \\
\text { Interferón beta-1 } \\
\text { Metilprednisolona en bolos } \\
\text { Tocilizumab } \\
\text { HBPM, dosis intermedia o anticoagulante }\end{array}$ & $\begin{array}{c}15 \\
15 \\
14 \\
6 \\
11 \\
6 \\
13\end{array}$ & $\begin{array}{l}87 \\
87 \\
78 \\
33 \\
61 \\
33 \\
72\end{array}$ \\
\hline $\begin{array}{l}\text { Complicaciones } \\
\text { Síndrome confusional agudo } \\
\text { Descompensación diabética } \\
\text { Sobreinfección respiratoria bacteriana }\end{array}$ & $\begin{array}{l}4 \\
2 \\
1\end{array}$ & $\begin{array}{c}22 \\
11 \\
5\end{array}$ \\
\hline Mortalidad intrahospitalaria & 2 & 11 \\
\hline
\end{tabular}

$\mathrm{DE}=$ desviación estándar, $\mathrm{SDR}=$ síndrome de dificultad respiratoria, $\mathrm{HBPM}=$ heparina de bajo peso molecular.

(33\%), bolos de metilprednisolona (61\%), tocilizumab (33\%) y heparinas de bajo peso molecular a dosis intermedias 0 anticoagulantes (72\%). Las complicaciones más comunes durante el ingreso fueron el síndrome de confusión aguda (22\%) y la diabetes inducida por corticosteroides (11\%). Las superinfecciones respiratorias bacterianas representaron solo $6 \%$ (Tabla 1). La estancia media fue de $9.4 \pm 5.3$ días y la mortalidad hospitalaria, de $11 \%$.

Respecto al plan de coordinación con los centros de salud social, de 827 residentes de los 11 centros geriátricos del distrito (Figura 1) se incluyeron 50, cuatro $(0.48 \%)$ positivos a SARS-CoV-2. El síntoma común en los cuatro casos fue fiebre alta; tres también presentaron tos no productiva y solo uno, disnea; tres fueron tratados en la residencia con hidroxicloroquina durante cinco días y azitromicina por tres días, además de antibióticos prescritos en forma empírica; el cuarto se trataba de un paciente con gran dependencia previa, por lo cual fue trasladado al hospital regional, ya que no se podía garantizar la atención médica adecuada en el centro geriátrico debido a la falta de personal médico o de enfermería. Durante el seguimiento del programa se realizaron pruebas de PCR a todos los residentes y trabajadores $(n=519)$, se realizaron 1044 llamadas telefónicas y se evitaron 36 hospitalizaciones, con un ahorro estimado en costos directos de 111396.87 euros.

\section{Discusión}

Los pacientes estudiados eran ancianos, en su mayoría del sexo masculino y con comorbilidades, como se ha descrito en estudios previos. ${ }^{3-5}$ Ninguno experimentó enfermedad tromboembólica clínica, evento que se está registrando con mayor recurrencia en la literatura. ${ }^{6}$ En ausencia hasta la fecha de un tratamiento efectivo contra COVID-19, la piedra angular del manejo es la prevención de la transmisión, que a nivel comunitario se lleva a cabo mediante el confinamiento temprano y tratando de que los individuos infectados se mantengan en su domicilio habitual durante la enfermedad, siempre que sea posible. Es probable que esta medida sea la clave fundamental para la baja tasa de transmisión en el distrito de salud que cubre el Hospital Público de Monforte, junto con la implementación de circuitos COVID y no COVID absolutamente separados y la puesta en marcha de una red dinámica de atención domiciliaria, que en otros estudios recientes ha demostrado ser relevante. ${ }^{7}$

El tratamiento médico se basó en hidroxicloroquina y azitromicina, como se indica en los estudios iniciales. ${ }^{6}$ También se aplicó heparina de bajo peso molecular, a dosis intermedia para profilaxis; incluso, en casos seleccionados, a dosis anticoagulante, teniendo en cuenta que el SARS-CoV-2 es extremadamente protrombogénico. $^{8}$

La estancia hospitalaria de nueve o 10 días fue menor que la descrita en la literatura, pues las muertes ocurrieron en los primeros 15 días y los casos que evolucionaron adecuadamente egresaron en menos de dos semanas.

Al tratarse de una serie pequeña, la mortalidad no permite una interpretación rigurosa, sin embargo, fue 


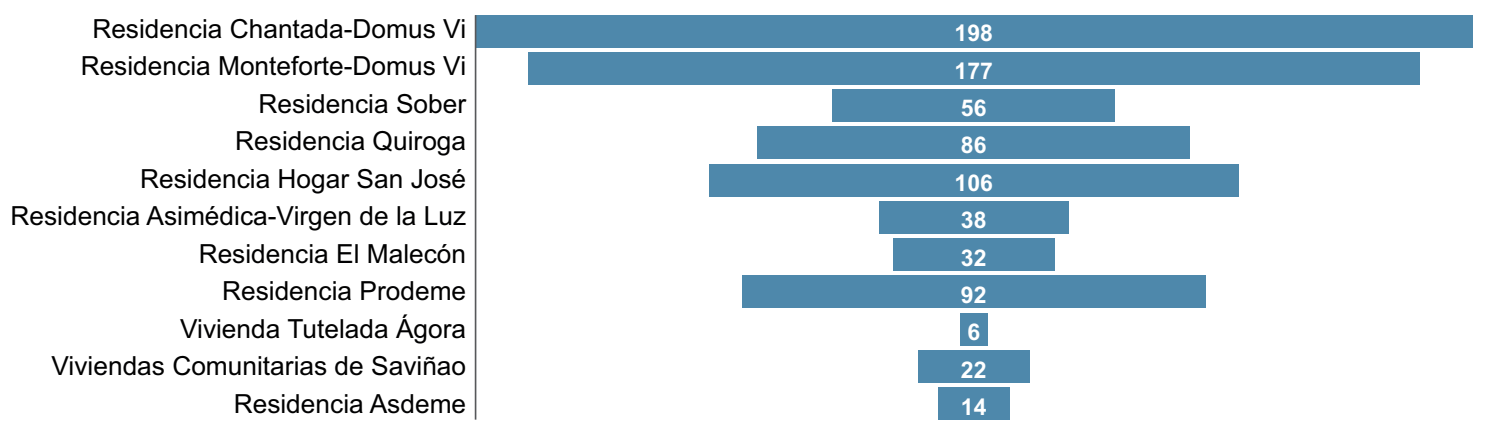

Figura 1. Número de residentes por centro geriátrico.

levemente superior a la global., ${ }^{9,10}$ A pesar de las limitaciones de este estudio, como el pequeño tamaño de la muestra que hace imposible realizar inferencias, en estos momentos de incertidumbre es necesaria la difusión de datos veraces que aumenten progresivamente el conocimiento acerca de COVID-19.

\section{Conclusiones}

Nuestros resultados indicaron una baja incidencia de casos de COVID-19 registrados en los centros de salud social, quizá por el confinamiento temprano, la dispersión de la población, el manejo combinado entre el hospital y la atención sociosanitaria, así como el traslado de los pacientes solo por motivos esenciales.

El perfil del paciente COVID-19 que ingresó al Hospital Público de Monforte fue similar al documentado en la literatura; la mayor mortalidad se debió principalmente a la comorbilidad significativa y a la edad avanzada. Se destaca la baja incidencia de casos de COVID-19 registrados en los centros de salud social del Distrito Sanitario de Monforte de Lemos. Entre las razones principales se encuentran el trabajo multidisciplinario y la atención centrada en el paciente, que se realiza de forma transversal entre el entorno hospitalario y el residencial; además de la realización exhaustiva de la prueba de PCR en los residentes y trabajadores de los centros geriátricos. Otros factores que influyeron en la baja incidencia de casos son la dispersión geográfica de la población del distrito y el decreto del estado de alarma y confinamiento antes de casos documentados en la región.

\section{Conflicto de intereses}

Los autores declaran no tener conflicto de intereses alguno.

\section{Financiamiento}

Los autores no recibieron patrocinio para llevar a cabo este artículo.

\section{Responsabilidades éticas}

Protección de personas y animales. Los autores declaran que para esta investigación no se realizaron experimentos en seres humanos ni en animales.

Confidencialidad de los datos. Los autores declaran que han seguido los protocolos de su centro de trabajo sobre la publicación de datos de pacientes.

Derecho a la privacidad y consentimiento informado. Los autores han obtenido el consentimiento informado de los pacientes y/o sujetos referidos en el artículo. Este documento obra en poder del autor de correspondencia.

\section{Bibliografía}

1. Paules $\mathrm{Cl}$, Marston HD, Fauci AS. Coronavirus infections-more than just the common cold. JAMA. 2020;323:707-708. DOI:10.1001/jama.2020.0757

2. López-Reboiro M, Sardiña-González C, López-Castro J. COVID-19 y Argumentum ad ignorantiam o "no todo vale". Rev Clin Esp. Rev Clin Esp. 2020 May 4. DOI: 10.1016/j.rce.2020.04.01

3. Chen N, Zhou M, Dong X, Qu J, Gong F, Han Y, et al. Epidemiological and clinical characteristics of 99 cases of 2019 novel coronavirus pneumonia in Wuhan, China: a descriptive study. Lancet. 2020;395:507-513.

4. Guan W, Ni Z, Hu Y, Liang W, Ou C, He J, et al. Clinical characteristics of coronavirus disease 2019 in China. N Engl J Med. 2020;382:1708-1720.

5. Wang B, Li R, Lu Z, Huang Y. Does comorbidity increase the risk of patients with COVID-19: Evidence from meta-analysis. Aging (Albany NY). 2020;12:6049-6057.

6. Zhou F, Yu T, Du R, Fan G, Liu Y, Liu Z et al. Clinical course and risk factors for mortality of adult inpatients with COVID-19 in Wuhan, China: A retrospective cohort study. Lancet. 2020;395:1054-1062.

7. Sánchez-Duque JA, Arce-Villalobos LR, Rodríguez-Morales AJ. Coronavirus disease 2019 (COVID-19) in Latin America: Role of primary care in preparedness and response. Aten Primaria. 2020;52:369-372.

8. López Castro J. COVID-19 and thrombosis: Beyond a casual association. Med Clin (Barc). 2020.

9. Wang X, Fang X, Cai Z, Wu, X., Gao, X., Min, J. et al. Comorbid chronic diseases and acute organ injuries are strongly correlated with disease severity and mortality among COVID-19 patients: A systemic review and meta-analysis. Research (Wash D C). 2020;2020:2402961.

10. Jan H, Faisal S, Khan A, Khan S, Usman H, Liaqat R, et al. COVID-19: Review of epidemiology and potential treatments against 2019 novel coronavirus. Discoveries (Craiova). 2020;8:e108. 